\title{
Seasonal Trends in the Occurrence of Eclampsia
}

\author{
${ }^{1}$ Shaheen Kausar, ${ }^{2}$ Alia Bashir, ${ }^{3}$ Ahmad Malik, ${ }^{4}$ Mamoon Akbar Qureshi
}

\section{ABSTRACT}

Background: Preeclampsia and eclampsia are major obstetric complications with unclear etiologies. Understanding the exact association with different weather patterns may help us in understanding what factors may be involved in triggering these events. Lower temperature, higher humidity and lower barometric pressure are linked to eclampsia.

Objective: To know the relation between variations of weather and incidence of eclampsia in patients presenting in, Jinnah Hospital, Lahore.

Materials and methods: Total number of deliveries and patients presenting with eclampsia were recorded from January 2008 to December 2012. Meteorological data was acquired from the regional meteorological center recording the monthly average temperature, humidity, barometric pressure and rainfall during the study period. The incidence of eclampsia and the seasonal trend were analyzed for Maximum (MMM) temperature, humidity at $5 \mathrm{pm}, 5 \mathrm{pm}$ atmospheric pressure (ATM) and rainfall.

Study design: Cross sectional study

Study setting: Gyne Unit 2, Jinnah Hospital, Lahore

Results: Over a 60-month period, a total of 31,331 deliveries were recorded, of which 579 patients developed eclampsia $(1.85 \%)$. There was a statistically significant Pearson's correlation coefficient, the incidence of eclampsia was found to increase with MMM 5 pm temperature $(0.516, p<0.05)$ and rainfall $(0.427, p<0.05)$ and 5 pm ATM atmospheric pressure $(-0.501, p<0.05)$. No significant correlation was found with humidity $(0.093, p>0.05)$.

Conclusion: Incidence of eclampsia has direct linear relationship with increased temperature and rainfall and inverse relationship with $5 \mathrm{pm}$ atmospheric pressure. The humidity had no apparent effect.

Keywords: Eclampsia, Weather, Climate, Temperature, Humidity, Atmospheric pressure.

\footnotetext{
${ }^{1}$ Associate Professor, ${ }^{2}$ Assistant Professor, ${ }^{3}$ House Officer ${ }^{4}$ Senior Lecturer

${ }^{1}$ Department of Gynecology and Obstetrics, Unit V, King Edward Medical University/Lady Aitchison Hospital, Lahore Pakistan

${ }^{2}$ Department of Gynecology and Obstetrics, Unit II, Allama Iqbal Medical College/Jinnah Hospital, Lahore, Pakistan

${ }^{3}$ Department of Medicine, Allama Iqbal Medical College/Jinnah Hospital, Lahore, Pakistan

${ }^{4}$ Department of Community Medicine, Allama lqbal Medical College, Lahore, Pakistan
}

Corresponding Author: Shaheen Kausar, Associate Professor, B-77, GOR III, Shadman, Lahore, Pakistan, Phone: +92-300-9473802, e-mail: drskmalik@hotmail.com
How to cite this article: Kausar S, Bashir A, Malik A, Qureshi MA. Seasonal Trends in the Occurrence of Eclampsia. J South Asian Feder Obst Gynae 2014;6(2):83-87.

\section{Source of support: Nil}

Conflict of interest: None declared

\section{INTRODUCTION}

Eclampsia is defined as the occurrence of convulsions, not caused by coincidental neurologic disease (e.g. epilepsy), in a woman whose condition meets the criteria for preeclampsia. ${ }^{1}$ When convulsions occur during pregnancy, delivery or puerperium, the diagnosis of eclampsia is made until proven otherwise.

Despite the reported reduced incidence in the Western World, eclampsia remains a significant cause of maternal mortality all over the world. ${ }^{2-4}$ Preeclampsia and eclampsia are major obstetric complications with unclear etiologies. Understanding the exact association with different weather patterns may help us in understanding what factors may be involved in triggering these events. Lower temperature, higher humidity and lower barometric pressure are linked to eclampsia. ${ }^{5}$ Exploring this association will help us to gain further insight into the pathophysiology of this condition.

Dietary intake and risk of infection varies with season. Also, ambient temperature and the amount of daylight can show relatively large seasonal variations. If such factors were important for the etiology of preeclampsia, systematic seasonal patterns in the prevalence of this disorder are expected. In reviews of the etiology and epidemiology of preeclampsia, seasonal trends are not mentioned. ${ }^{6,7}$

An old account from Norway claims that eclampsia appears to increase in frequency during autumn and winter. ${ }^{8}$ In Ghana, more cases of eclampsia have been noted in the rainy season, ${ }^{9}$ and a report from Singapore showed that the prevalence of preeclampsia in the hot, dry months of February, March and April was about twice as high as in the months of October, November and December. ${ }^{10}$ Recently, a seasonal pattern was described in Zimbabwe, with an increase at the end of the dry season and in the first months of the rainy season (November-March). ${ }^{11}$ In Kuwait, the prevalence of preeclampsia was highest in November, when the temperature was relatively low and the humidity high. ${ }^{12}$ In a study of 10,666 pregnant women in Sweden it was found that there was a reduced prevalence of preeclampsia in summer compared with winter. ${ }^{13}$ 


\section{OBJECTIVES}

- To estimate the seasonal pattern in the prevalence of eclampsia.

- To assess whether a correlation exists between the incidence of eclampsia and various weather parameters.

\section{MATERIALS AND METHODS}

We retrospectively analyzed data from Gyne Unit II, Jinnah Hospital, Lahore, over a period of 60 months from January 2008 to December 2012, recording the incidence of eclampsia in our patients who come for delivery. Meteorological data was acquired from the regional meteorological center recording the monthly average temperature, humidity, barometric pressure and rainfall during the study period. The incidence of preeclampsia and eclampsia and the meteorological differences between the seasons were compared.

The incidence of eclampsia for each month was estimated as the number of births for which eclampsia had been noted divided by all births during the month. The meteorological data for the said period was obtained from Pakistan Meteorological Department, Lahore. The data was then compared with the help of Tables 1,2, and Graphs 1 to 6 .

\section{RESULTS}

Over a 60-month period, a total of 31,331 deliveries were recorded, of which 579 patients developed eclampsia $(1.85 \%)$.
The results were compared using Pearson's correlation coefficient. There was a statistically significant Pearson's correlation coefficient, the incidence of eclampsia was found to increase with MMM $5 \mathrm{pm}$ temperature $(0.516, \mathrm{p}<0.05)$ and rainfall $(0.427, \mathrm{p}<0.05)$ and $5 \mathrm{pm}$ ATM pressure $(-0.501$, $\mathrm{p}<0.05)$. No significant correlation was found with humidity $(0.093, \mathrm{p}>0.05)$. The incidence was increased from May through September every year which coincides with the summer temperature and monsoon rainfall. In this time, the humidity was variable while the atmospheric pressure was low. The correlation is more accurately observed in the graphs shown.

\section{DISCUSSION}

Eclampsia remains a problem in the developing world despite improvements in antenatal care and facilities. ${ }^{14}$ It is also a major cause of maternal mortality. The etiology of preeclampsia and eclampsia is not fully understood.

We found a systematic seasonal variability in the occurrence of eclampsia with a peak in the summer months and minimum in the winter. Our observations and the seasonal trends reported from other countries, point to environmental factors that show seasonal variability in occurrence. The effect of cold weather on the ischemia which is assumed to be the basis of the relatively strong association between outdoor temperature and the occurrence of myocardial infarction ${ }^{15}$ could be an analogy.

Table 1: Incidence of eclampsia with weather changes in 2008 to 2012

\begin{tabular}{llllllll}
\hline 2008-2012 & Total births & Eclampsia & $\%$ & $\begin{array}{l}\text { MMM } \\
\text { temperature }\end{array}$ & $\begin{array}{l}\text { Humidity at } \\
5 p m\end{array}$ & $\begin{array}{l}5 \text { pm ATM } \\
\text { pressure }\end{array}$ & Rainfall \\
\hline January & 2563 & 23 & 0.90 & 17.96 & 55.2 & 996.58 & 12.6 \\
February & 2271 & 18 & 0.79 & 21.76 & 45.8 & 993.48 & 15.36 \\
March & 2315 & 39 & 1.68 & 29.10 & 38.4 & 989.38 & 14.94 \\
April & 2237 & 47 & 2.10 & 34.26 & 28.0 & 985.56 & 22.54 \\
May & 2784 & 60 & 2.16 & 39.20 & 23.6 & 980.20 & 11.24 \\
June & 2736 & 69 & 2.52 & 38.86 & 35.6 & 977.18 & 50.8 \\
July & 3017 & 79 & 2.62 & 35.92 & 57.6 & 977.20 & 159.7 \\
August & 3108 & 64 & 2.06 & 35.14 & 65.6 & 980.08 & 189.92 \\
September & 2891 & 61 & 2.11 & 33.66 & 59.2 & 983.88 & 96.94 \\
October & 2649 & 42 & 1.59 & 32.22 & 44.0 & 989.04 & 7.54 \\
November & 2333 & 42 & 1.80 & 27.22 & 46.2 & 992.80 & 0.26 \\
December & 2427 & 35 & 1.44 & 21.48 & 53.2 & 994.06 & 8.76 \\
\hline Total & 31331 & 579 & 1.85 & & & &
\end{tabular}

Table 2: Five years correlation between incidence of eclampsia and seasonal variation

\begin{tabular}{|c|c|c|c|c|c|}
\hline & & $\begin{array}{l}\text { MMM } 5 \text { pm } \\
\text { temperature }\end{array}$ & $\begin{array}{l}\text { Humidity } \\
\text { at } 5 \mathrm{pm}\end{array}$ & $\begin{array}{l}5 \text { pm ATM } \\
\text { pressure }\end{array}$ & Rainfall \\
\hline \multirow[t]{3}{*}{ Incidence of eclampsia } & Pearson correlation & $0.516^{\star \star}$ & 0.093 & $-0.501^{\star \star}$ & $0.427^{* *}$ \\
\hline & Sig. (two-tailed) & 0.000 & 0.479 & 0.000 & 0.001 \\
\hline & $\mathrm{N}$ & 60 & 60 & 60 & 60 \\
\hline
\end{tabular}

${ }^{* *}$ Correlation is significant at the 0.01 level (two-tailed); Correlation is significant at the 0.05 level (two-tailed) 


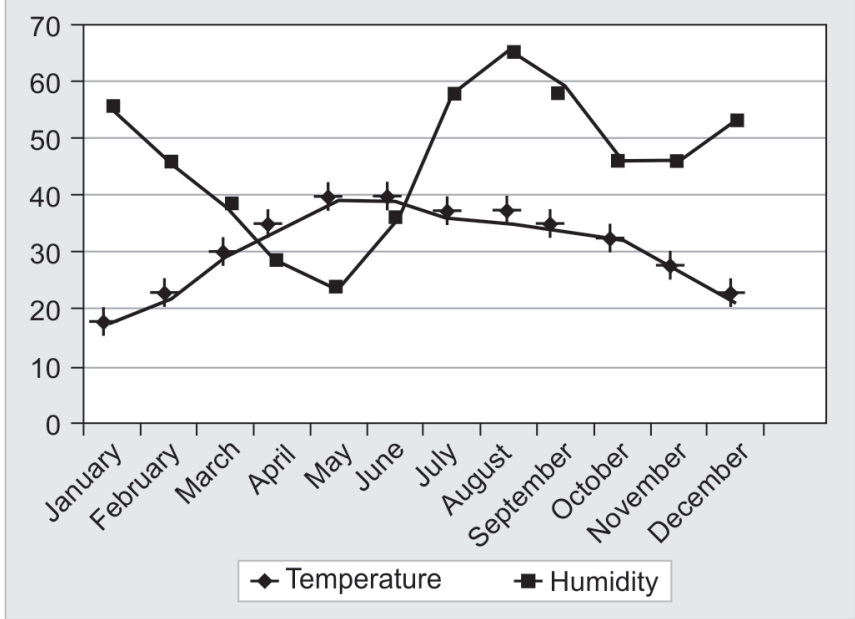

Graph 1: Variation in temperature and humidity

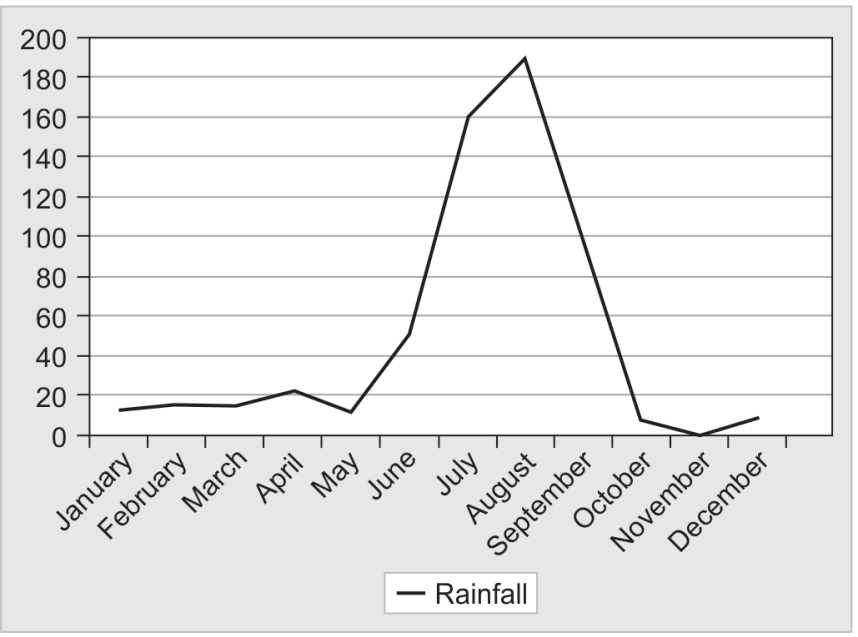

Graph 3: Variation in rainfall

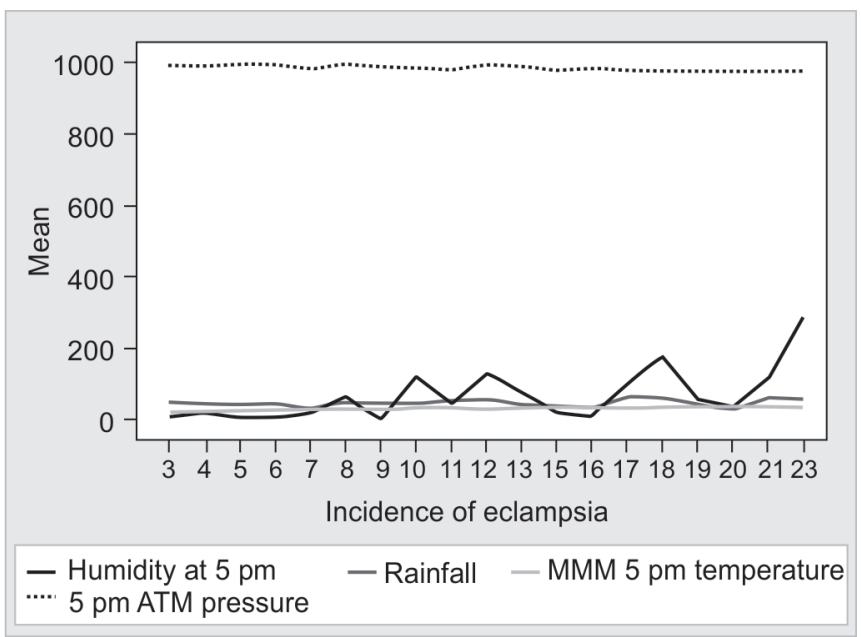

Graph 5: Incidence of eclampsia and humidity, rainfall and temperature changes

Calcium, ${ }^{16}$ fish oil,${ }^{17}$ antioxidants ${ }^{18}$ and homocysteine ${ }^{19}$ have been thought to possibly play causal roles in preeclampsia. Seasonal variability in dietary intake may be relevant for understanding the seasonal variation in occurrence of preeclampsia.

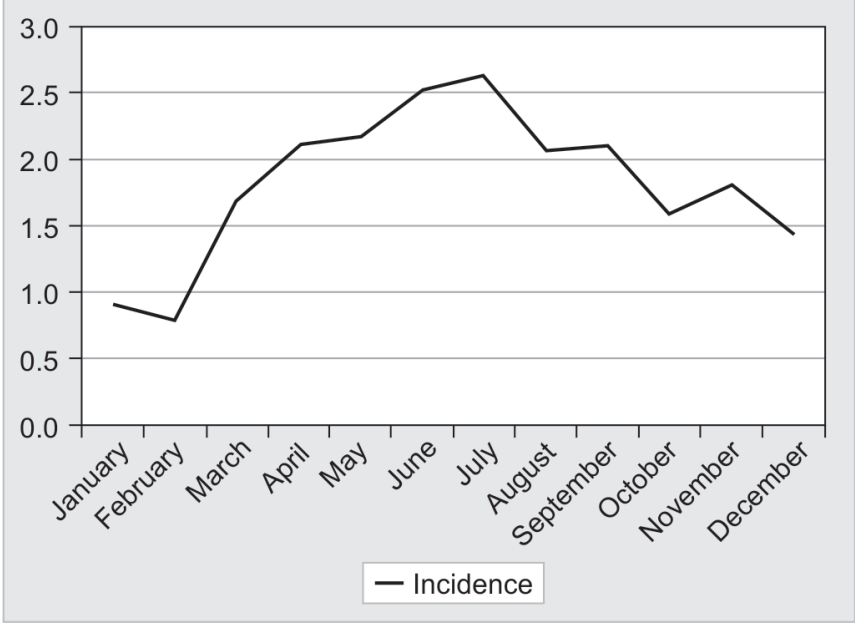

Graph 2: Variation in incidence

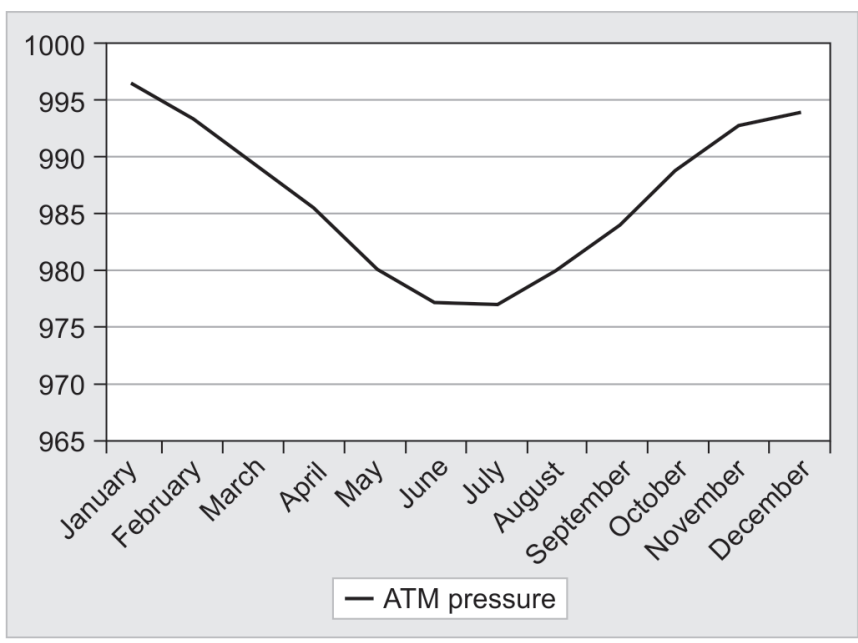

Graph 4: Variation in ATM pressure

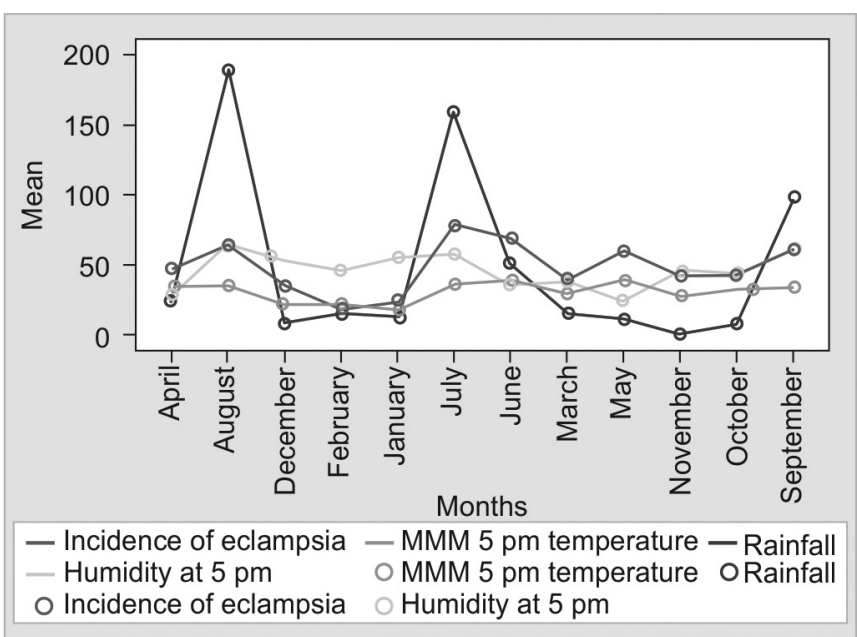

Graph 6: Monthly variation in incidence of eclampsia and humidity, rainfall and temperature changes

There are two studies which demonstrate no relationship of meteorological factors on the incidence of eclampsia. ${ }^{20,21}$ Most data, however, tend to suggest that eclampsia is associated with cooler temperatures or winter or with increased humidity or rainfall. ${ }^{22-24}$ On the contrary, Griswold et al in 
their study from Florida, USA, suggest higher incidence of eclampsia in the hurricane weather, which is characterized by higher temperatures rather than lower, increased humidity and reduced barometric pressures. ${ }^{25}$ Majority of published studies conclude that preeclampsia occurs more frequently in winter. ${ }^{26-29}$ Conversely, Tan et al have suggested that preeclampsia is common in summer. ${ }^{30}$ Wacker et al found no statistically different frequency of preeclampsia in the dry and wet seasons that occur in Zimbabwe. ${ }^{31}$ All these studies have assessed if there was a seasonal variation in the incidence of preeclampsia. Interestingly Phillips et al, in their study, have evaluated the link between the timing of conception with risk of preeclampsia. ${ }^{32}$ They found the highest risk of preeclampsia in conceptions occurring in the summer season, whereas there was no significant variation in the incidence of preeclampsia based on the timing of delivery.

It is interesting that while the studies in sub-Saharan Africa show a relationship between seasons and occurrence of eclampsia, two studies in the United States concluded that the incidence of eclampsia was not influenced by climatic factors even in periods of high humidity. ${ }^{33,34} \mathrm{An}$ interesting study in Norway concluded that there was a relationship between preeclampsia and seasons with a higher incidence during colder seasons. ${ }^{28}$ The data in that study spanned a twenty-one year period. The study is important coming from a wealthy nation where access to health care services is not a problem (prenatal care is free), unlike studies from other nations with more diversity and poverty. The study emphasized the possible role of environmental factors like diet during the seasons. We aim to assess the association of preeclampsia and eclampsia with various weather parameters in this unique climatic condition.

A lot of emphasis has been placed on good antenatal care and improved standard of living in most of the studies on eclampsia. Most of the women register for antenatal care in various hospitals and maternities, but are usually referred to Jinnah hospital Lahore, with complications in labor because of good ICU facilities.

\section{CONCLUSION}

- Incidence of eclampsia has direct linear relationship with increased temperature and rainfall and inverse relationship with 5 pm ATM pressure.

- The humidity had no apparent effect.

\section{REFERENCES}

1. American College of Obstetricians and Gynecologists management of pre-eclampsia Technical Bulletin number 91, Washington DC; February 1991.

2. Mattar F, Sibai BM. Eclampsia. VIII- Risks factors for maternal mortality. Am J Obstet Gynaecol 2000;182(2):307-312.
3. Sawhney H, Aggarwal N, Biswas R, Vasishta K, Gopalan S. Maternal mortality associated with eclampsia and severe preeclampsia of pregnancy J. Obstet Gynaecol Res 2000;26(5): 351-356.

4. Onuh SO, Aisien AO. Maternal and fetal outcome in eclamptic patients in Benin City, Nigeria. J Obstet Gynaecol 2004; 24(7):765-768

5. Seasonal variation in the incidence of preeclampsia and eclampsia in tropical climatic conditions. Vidya Subramaniam, Department of Obstetrics and Gynaecology, Bassetlaw Hospital, Blyth Road, Workshop, Nottinghamshire, UK BMC Women's Health 2007;7:18doi:10.1186/1472-6874-7-18.

6. Zhang J, Zeisler J, Hatch MC, Berkowitz G. Epidemiology of pregnancy-induced hypertension. Epidemiol Rev 1997;19: 218-232.

7. Dekker GA, Sibai BM. Etiology and pathogenesis of preeclampsia: current concepts. Am J Obstet Gynecol 1998;179:13591375.

8. Aall C. Eklampsived Kristiania fødselsstiftelse (Eclampsia at Kristiania Birth Clinic) 1895-1904. J Nor Med Assoc 1905;1: 114-117.

9. Obed SA, Wilson JB, Elkins TE. Eclampsia: 134 consecutive cases. Int J Gynecol Obstet 1994;45:97-103.

10. Tan GWT, Salmon YM. Meteorological factors and preeclampsia. Sing Med J 1988;29:133-137.

11. Wacker J, Schulz M, Fruhauf J, Chiwora FM, Solomayer E, Bastert G. Seasonal change in the incidence of pre-eclampsia in Zimbabwe. Acta Obstet Gynecol Scand 1998;77:712 -716.

12. Makhseed M, Musini VM, Ahmed MA, Monem RA. Influence of seasonal variation on pregnancy-induced hypertension and/ or preeclampsia. Aust NZ J Obstet Gynecol 1999;39: 196-199.

13. Ros HS, Cnattingius S, Lipworth L. Comparison of risk factors for preeclampsia and gestational hypertension in a populationbased cohort study. Am J Epidemiol 1998;147:1062-1070.

14. Moodley J, Daya P. Eclampsia: a continuing problem in the developing countries. Int J Gynaecol Obstet 1994;44 (1):9-14.

15. Rose G. Cold weather and ischemic heart disease. Br J PrevSoc Med 1966;20:97-100.

16. Levine RJ, Hauth JC, Curet LB, et al. Trial of calcium to prevent preeclampsia. New Engl J Med 1997;337:69-76.

17. Salvig JD, Oslen SF, Secher NJ. Effects of fish oil supplementation in late pregnancy on blood pressure: a randomized controlled trial of fish oil in high risk pregnancy. Br J Obstet Gynaecol 1996;103:529-533.

18. Chappell LC, Seed PT, Briley AL, et al. Effect of antioxidants on the occurrence of pre-eclampsia in women at increased risk: a randomized trial. Lancet 1999;354:810-816.

19. Rajkovic A, Catalano PM, Malinow MR. Elevated homocysteine levels with preeclampsia. Obstet Gynecol 1997;90:168-171.

20. Alderman BW, Boyko EJ, Loy GL, Jones RH, Keane EM, Daling JR. Weather and occurrence of eclampsia. Int J Epidemiol 1988;17(3):582-588.

21. Magann EF, Perry KG Jr, Morrison JC, Martin JN Jr. Climatic factors and preeclampsia-related hypertensive disorders of pregnancy. Am J Obstet Gynecol 1995;172(1 Pt 1):204-205.

22. Neela J, Raman L. Seasonal trends in the occurrence of eclampsia. Natl Med J India 1993;6(1):17-18.

23. Neutra R. Meteorological factors and eclampsia. J Obstet Gynaecol Br Commonw 1974;81(11):833-840.

24. Agobe JT, Good W, Hancock KW. Meteorological relations of eclampsia in Lagos, Nigeria. Br J Obstet Gynaecol 1981; 88(7):706-710. 
25. Griswold DM, Cavanagh D. Eclampsia and the weather. Am J Obstet Gynecol 1965 Mar 15;91:847-851.

26. Bider D, Sivan E, Seidman DS, Dulitzky M, Mashiach S, Serr $\mathrm{DM}$, Ben-Rafael Z. Meteorological factors in hypertensive disorders, vaginal bleeding and premature rupture of membranes duringpregnancy. Gynecol Obstet Invest 1991;32(2):88-90.

27. Makhseed M, Musini VM, Ahmed MA, Monem RA: Influence of seasonal variation on pregnancy-induced hypertension and/or preeclampsia. Aust NZ J Obstet Gynaecol 1999; 39(2):196-199.

28. Magnus P, Eskild A. Seasonal variation in the occurrence of preeclampsia. BJOG 2001;108(11):1116-1119.

29. Ros HS, Cnattingius S, Lipworth L. Comparison of risk factors for preeclampsia and gestational hypertension in a population based cohort study. Am J Epidemiol 1998 Jun 1;147(11):10621070 .
30. Tan GW, Salmon YM. Meteorological factors and pre-eclampsia. Singapore Med J 1988;29(2):133-137.

31. WackerJ, SchulzM, FruhaufJ, ChiworaFM, SolomayerE, BastertG. Seasonal change in the incidence of preeclampsia in Zimbabwe. Acta Obstet Gynecol Scand 1998;77(7):712-716.

32. Phillips JK, Bernstein IM, Mongeon JA, Badger GJ. Seasonal variation in preeclampsia based on timing of conception. Obstet Gynecol 2004;104(5 Pt 1):1015-1020.

33. Alderman BW, Boyko EJ, Loy GL, Jones RH, Keane EM, Daling JR. Weather and occurrence of eclampsia. Int J Epidemiol 1988; 17(3):582-588.

34. Magann EF, Perry KG Jr, Morrison JC, Martin JN Jr. Climatic factors and pre-eclampsia related hypertensive disorders of pregnancy. Am J Obstet Gynecol 1995;172(1 pt 1): 204-205. 